\title{
AS NARRATIVAS CONTEMPORÂNEAS E AS FRONTEIRAS ENTRE REALIDADE E IMAGINÁRIO: UMA ANÁLISE DOS PROCESSOS DE AUTOFICCIONALIZAÇÃO EM DIVÓRCIO
}

\author{
Keyla Silva Rabêlo \\ Doutoranda em Letras - Língua Portuguesa - pela Universidade do Estado do Rio de \\ Janeiro (UERJ) \\ keurabelo@yahoo.com.br
}

\section{RESUMO}

A proposta deste ensaio é apresentar uma reflexão sobre a obra "Divórcio", do escritor paulista Ricardo Lísias, a fim de identificar, em sua narrativa, as estratégias por ele usadas para compor uma estrutura em que, na língua e pela língua, se entrelaçam o real e o imaginário. A discussão aqui apresentada está ancorada nos estudos críticos e literários sobre a autoficção e nos pressupostos da perspectiva discursiva dialógica através do debate que traz sobre linguagem, produção de sentidos, gêneros textuais e intergenerecidade.

Palavras-chave: autoficcionalização, narrativas contemporâneas,

\section{ABSTRACT}

The purpose of this essay is to reflect upon the book "Divórcio", written by Ricardo Lísias, a writer from São Paulo. The intent is to identify, in Lísias' narrative, the strategies he uses to compose a structure in which, in language and by language, the real and the imaginary are interlaced. The discussion here is anchored in critical and literary studies about autofiction and in the assumptions of the discursive dialogical perspective through the debate that brings about language, production of meanings, textual genres and intergenerecity.

Keywords: autoficcionalization, contemporary narratives, subjectivities.

subjetividades. 


\section{Introdução}

Há, neste artigo, a tentativa de relacionar as características da narrativa contemporânea - em especial, a obra "Divórcio" - às discussões procedentes dos estudos críticos e literários sobre a autoficção.

Como não há consenso no que se refere à definição de autoficção e considerando o que nos aponta Figueiredo (2013) sobre o próprio surgimento do termo - que, segundo a autora, contribuiu para embaralhar ainda mais a questão, ao juntar, de maneira paradoxal, numa mesma palavra, duas formas de escrita que, em princípio, deveriam se opor -, a estratégia adotada aqui consistirá em estabelecer um diálogo entre a obra analisada e textos teóricos de grande relevância na área.

Desse modo, este texto estará organizado seguindo um trajeto bastante direto: inicialmente, apresentação de um breve resumo do livro objeto de análise (Divórcio); em seguida, serão trazidas à tona algumas questões de linguagem identificadas na construção da narrativa baseadas nos pressupostos da perspectiva discursiva dialógica; e, finalmente, reflexões sobre os processos de ficcionalização que, dentre outros, envolvem as fronteiras existentes entre identidade/subjetividades, vida/obra e autor/personagem.

\section{Entrando em cena: a narrativa}


O escritor paulistano Ricardo Lísias lançou em 2013 o romance Divórcio, uma obra em que são utilizados elementos biográficos, uma tendência da literatura contemporânea, para construir o personagem principal de sua trama, o também escritor Ricardo Lísias.

O foco narrativo se constitui através de um narrador autodiegético que se caracteriza, segundo Carlos Reis (1996), como uma entidade responsável por uma situação ou atitude narrativa específica: aquela em que o narrador da história relata as suas próprias experiências como personagem central da história.

Tudo começa quando Ricardo Lísias, após quatro meses de casado, encontra, por acaso, o diário de sua esposa:

Lembrei-me de uma conta que precisava pagar naquele dia. Abri a gaveta da minha ex-mulher e vi o boleto no meio de seu caderno. Li uma frase e minhas pernas perderam a força. Sentei no lado dela da cama e por um instante lutei contra mim mesmo para tomar a decisão mais difícil de minha vida. Resolvi por fim ler o diário da primeira à última linha de uma vez só (LíSIAS, 2013, p. 25).

As revelações contidas no diário, principalmente no que diz respeito às descrições feitas por sua ex-mulher em relação à imagem que tinha dele - "O Ricardo é patético", "Casei com um homem que não viveu", "Eu não tenho nada para sonhar com ele", "A pessoa consegue ser professor de Princeton, mas não sabe usar talher em um restaurante um pouco melhor" - fizeram com que o personagem se sentisse morto, com o corpo sem pele:

A gente vive a morte acordado. (LÍSIAS 2013, p. 7) 
Li o diário e saí de casa no dia 6 de agosto de 2011, mais ou menos às onze horas da manhã. Poucos dias depois, tive certeza de ter morrido. Meu corpo sem pele jazia na cama que eu tinha colocado no cafofo. Foi o segundo funeral em que estivesse na vida: antes, só o da minha avó [...] (LÍSIAS, 2013, p. 35-36).

A partir daí, o personagem, transtornado e com seu corpo "desnudo, sem pele", faz uma cópia do diário, divorcia-se e trava uma incessante guerra com sua ex-mulher:

[...] desgraçada, você está fazendo fofoca por aí? Desde quando eu te chantageei? Por acaso existe chantagem intermediada por advogado? Também soube que você está espalhando entre os jornalistas que, além de chantagista, sou ladrão [...]. Você tirou tudo o que eu tinha, fez o que fez com a minha vida e agora sai por aí espalhando mentiras! Tenha vergonha ao menos uma vez (LÍSIAS, 2013, p. 87-88).

Até decretar o reestabelecimento psicológico do personagem, o autor traz elementos que contribuem para a desestabilização das fronteiras existentes entre o real e o imaginário, uma estratégia para provocar o leitor e colocá-lo no jogo da narrativa.

\section{O fio condutor: a linguagem-movimento}

A linguagem, em sua dimensão literária, configura-se como um potente instrumento de possibilidades: há, através dela, um movimento dinâmico de transformação e de inscrição de sentidos que vai do racional, estático, pré-estabelecido ao subjetivo, criativo, imprevisível e expressivo.

Em "Divórcio", nota-se essa circularidade transgressora: em sua escrita, o autor apoia-se na exploração das inúmeras formas de expressão, quer seja na construção da descontinuidade da narrativa, quer seja na forma como nomeia seus personagens, no uso 
das metáforas ou de inúmeros gêneros discursivos dentro de seu romance. Nas palavras de Kramer (2001, p. 110), isso acontece porque escrever significa [...] sempre (re)escrever, interferir no processo, deixar-se marcar pelos traços do vivido e da escrita.

Nessa perspectiva, apresento a seguir como se configuram, na obra "Divórcio", estas formas de expressão indicadas anteriormente:

\section{a) Descontinuidade}

Seguindo os argumentos utilizados pelas teorias sociais (Hall, 2015) em que se discutem os acontecimentos recentes nas sociedades modernas e as consequências que esses acontecimentos têm gerado, principalmente, para a fragmentação das identidades, parte-se da seguinte ideia para explicar a descontinuidade da narrativa em "Divórcio":

a assim chamada "crise de identidade" é vista como parte de um processo mais amplo de mudança, que está deslocando as estruturas e processos centrais das sociedades modernas e abalando os quadros de referência que davam aos indivíduos uma ancoragem estável no mundo social (HALL, 2015, p. 9).

Essa mudança estrutural faz com que a linguagem assuma, também, uma nova dimensão. Sobre esse aspecto, Pires (1999), faz a seguinte observação:

O sentido da linguagem dissipa-se num jogo de intermináveis labirintos, indefinidos e conflituosos. Efemeridade, descontinuidade, parecem, pois, frequentemente constituir alguns dos termos definidores da atitude pós-moderna que, negando o eterno e imutável, mergulha na fragmentaridade da mudança (PIRES, 1999, p. 82). 
Essa descontinuidade é anunciada pelo próprio narrador de "Divórcio":

Outro defeito de "Divórcio" deve ser a descontinuidade. Muita coisa aparece, ensaia ganhar um fluxo e depois fica pelo caminho. Não sei se seria honesto creditar essa falha à condição do narrador. A recuperação do meu estado emocional teve idas e vindas, então é natural que detalhes tenham ficado para trás" (LíSIAS, 2013, p. 203).

Os impactos gerados pelas descobertas feitas no diário de sua ex-mulher fazem com que o personagem perceba a grande crise em que se encontra. Ele, um sujeito de identidade plenamente segura, coerente e estável, confrontava-se com uma experiência que lhe gerava dúvidas e incertezas.

Os fragmentos a seguir são exemplos de como isso ocorreu com o personagem:

Como vem acontecendo desde o início, perco-me em cada parágrafo do livro: não é isso. $O$ amor que eu sentia, grande ou não, não deixava nenhuma pergunta aparecer. Nunca dei espaço para que as dúvidas fundamentais surgissem: essa mulher é capaz até onde?, quais os limites que ela se impõe?, O que ela realmente procura todo dia quando acorda ao meu lado? (LíSIAS, 2013, p. 209).

A variação estilística do livro chama minha atenção. O começo é tenso e cheio de incertezas. Treme, por assim dizer. Acho que representa bem a situação de enorme angústia que vivi. Comecei a escrever exatamente depois da corrida que vou narrar no próximo capítulo. Ela me trouxe uma pele nova (LíSIAS, 2013, p. 212).

Depois da palpitação inicial, portanto, e do surto ter sido superado, eu precisava de algumas explicações. Por isso, o estilo varia e parece caminhar em direção a uma certa racionalidade. Hoje sei que estou estruturado de novo, embora tenha que sempre viver com uma lanterna no bolso: não quero ter outro surto. [...] (LíSIAS 2013, p. 212). 
b) As metáforas

Outro aspecto expressivo e de grande relevância para a construção narrativa de "Divórcio" é a utilização de pontes metafóricas entre o fato e a fiç̧ão o que, para Souza (2002, p. 111), possibilita a interpretação da literatura além de seus limites intrínsecos e exclusivos. O que conta na literatura não é propriamente o que está nas palavras, mas o que está entre as palavras (PROUST, 1954, p. 157 apud FIGUEIREDO, 2013, p. 16).

Foram identificadas as seguintes metáforas na obra analisada:

- A velocidade da narração: uma demonstração do desequilíbrio emocional em que se encontra o personagem após a descoberta do diário de sua ex-mulher:

Não consigo lembrar o motivo, mas resolvi descer os cinco andares de escada. Cumprimentei o porteiro. Não virei para saber quem estava fazendo barulho no salão onde tínhamos casado. Na rua, senti uma paz estranhíssima. Percebi que não podia ficar ali parado e desci uns cem metros. Então, fiz um raciocínio inesperado: acho que os próximos dias vão ser difíceis, preciso resolver algumas pendências. O que eu tenho de importante para fazer?" (LíSIAS, 2013, p. 26).

Minhas pernas estão fracas. Resolvo ir até o metrô. Uma pequena subida. Parece que a cidade está inteiramente muda. Não percebo o trânsito. Por mero acaso não fui atropelado. Preferi continuar na calçada. Gosto desse pequeno restaurante. As pessoas aqui comem pão na chapa porque querem fingir certo ar de desprendimento" (LÍSIAS, 2013, p. 27).

Nos capítulos finais, a recuperação do 'fôlego', a volta da estabilidade:

Dormi muito bem. A manhã demorou a passar. Fiquei o tempo inteiro organizando os últimos esboços de Divórcio. Nada me faria desistir do plano de começar o livro no 
dia 02 de janeiro. Minha cabeça se estruturou de novo. Comecei a rir. Não estou dentro de um texto que eu mesmo escrevi" (LíSIAS, 2013, p. 225).

- A nomeação dos capítulos: Os capítulos são nomeados em forma de quilômetros, quinze no total - "Quilômetro um: um corpo em carne viva"; "Quilômetro oito: meu marido é só um menino bobo"; "Quilômetro quinze: Octogésima Sétima Corrida Internacional de São Silvestre" -, e mais do que representar a distância a ser percorrida pelo personagem na corrida de São Silvestre, representa toda a travessia existencial pela qual ele passa (da descoberta do diário, da instauração do caos psicológico à recuperação);

- A pele: A exposição do corpo representa a dilaceração do sujeito, suas fragilidades em evidência; já a regeneração da pele, significa reestabelecimento do equilíbrio:

A dor de perder a pele é muito diferente da solidão (...) Descarnado, o tempo inteiro eu esperava alguém se aproximar e me dar uma explicação. Um corpo sem pele não consegue achar nenhuma resposta. A consequência é ainda pior: o ar começa a desaparecer" (LÍSIAS, 2013, p. 119).

Escrevo esse trecho um ano depois de sair de casa. Minha pele já voltou. Está novinha. Não sou a mesma pessoa, claro, mas superei quase tudo. Só tenho raiva de ser obrigado a levar essa história pelo resto da vida..." (LíSIAS, 2013, p. 173).

\section{c) Intergenerecidade}

Em todas as atividades da vida humana há uma relação com o uso da língua. As maneiras de utilização são tão variadas quanto as atividades. O homem é capaz de transmitir conhecimentos, fornecer informações, expressar sentimentos e conviç̧ões. 
Isso se dá porque "toda linguagem é dialógica, ou seja, todo enunciado é sempre um enunciado de alguém para alguém. Se assim não fosse, seria como uma ponte sem um dos lados para sustentação, o que levaria à sua derrocada" (MARCUSCHI, 2005, p. 7).

Sobre as relações dialógicas em conformidade com as ideias do círculo bakhtiniano, Faraco (2009) faz a seguinte observação:

Para haver relações dialógicas, é preciso que qualquer material linguístico (ou de qualquer outra materialidade semiótica) tenha entrado na esfera do discurso, tenha sido transformado num enunciado, tenha fixado a posição de um sujeito social. Só assim é possível responder (em sentido amplo e não apenas empírico do termo), isto é, fazer réplicas ao dito, confrontar posições, dar acolhida fervorosa à palavra do outro, confirma-la ou rejeitá-la, buscar-Ihe um sentido profundo, ampliá-la. Em suma, estabelecer com a palavra de outrem relações de sentido de determinada espécie, isto é, relações que geram significação responsivamente a partir do encontro de posições avaliativas (FARACO, 2009, p. 66).

Faraco (2009), nesse sentido, alerta para a constituição dos enunciados "não mais como unidade da língua, mas como um complexo de relações entre pessoas socialmente organizadas" (p. 66) e apresenta-nos o que Bakhtin (1970, apud Faraco 2009, p. 68) fala sobre a amplitude das relações dialógicas:

A compreensão estreita de dialogismo como debate, polêmica ou paródia. Estas são as formas externamente mais óbvias, embora rudimentares, de dialogismo. A confiança na palavra do outro, a recepção reverencial (a palavra de autoridade), o aprendizado, a busca pelo sentido profundo e sua natureza obrigatória, a concordância, suas infinitas gradações e nuanças (mas não suas limitações lógicas e restrições puramente referenciais), a estratificação de um significado que se sobrepõe a outro, de uma voz que se sobrepõe a outra voz, fortalecimento por meio da fusão (mas não identificação), a combinação de muitas vozes (um corredor de 
vozes) que amplia a compreensão, o afastamento para além dos limites do compreendido, e assim por diante.

Essa hibridização de vozes que se entrecruzam materializa-se nos mais diversos gêneros textuais com que lidamos cotidianamente. Assim, ao falar sobre intergenericidade, DELL'ISOLA (s/d, p. 1965) indica que todo texto é uma mescla ou mistura de textos, o que pode se dar através de várias formas, ou seja, tanto de maneira visível e transparente, como de modo implícito ou opaco. E acrescenta que:

O gênero híbrido aparentemente "infringe" convenções estabelecidas e caracterizase por uma estrutura em que há ruptura do convencional, do previsível, a qual parece se manifestar no texto sob a forma de uma incongruência, em que se espera do leitor uma "descoberta" de uma função social no texto que não está na superfície de sua macroestrutura. (DELL'ISOLA, s/d, p. 1706).

Ao falar sobre o caráter configurativo da narração a respeito do tempo, da experiência e da articulação dos acontecimentos, Arfuch (2010, p. 183) traz uma relevante contribuição que nos leva a pensar sobre o aspecto da intergenericidade:

A variação narrativa compreende não somente as grandes divisões canônicas dos gêneros, mas também as misturas e hibridações às quais eles são comumente submetidos no interior mesmo de suas lábeis fronteiras.

Nesse sentido, em "Divórcio", o autor faz uso do recurso da intergenericidade quando apresenta a seus interlocutores diversos gêneros discursivos - carta (p. 232 a 237), email (p. 168 a 170), obra científica (p. 114 e 115), diário (p. 80 e 81), sms (p. 15), anotações (p. 17) - com o propósito de estabelecer algum tipo de relação com o texto principal (o romance) e, assim, criar mais consistência à trama narrativa. 


\section{Nos entrelaces da trama: os processos de autoficcionalização}

Nesta seção, faz-se necessário estabelecer um diálogo entre o livro "Divórcio" e as discussões que trazem à tona questões referentes à identidade e à subjetividade e como isso tem influenciado a literatura contemporânea.

Vejamos a concepção de sujeito apresentada por Deleuze e Guattari:

Sim, existem sujeitos: são os grãos dançantes na poeira do visível, e lugares móveis num murmúrio anônimo. O sujeito é sempre uma derivada. Ele nasce e se esvai na espessura do que diz, do que se vê (DELEUZE; GUATTARI, 1992, p. 134).

Anunciam-se, aí, as características desse sujeito complexo - instável, descontínuo, em fluxo - ou, nas palavras de Signori (1998, p. 336), um ator que opera entre possibilidades disjuntas e/ou contraditórias, que (des)articula, que se faz nó, nexo, encruzilhada, a partir da multiplicidade heterogênea e polifônica dos códigos e narrativas sociais a que está exposto.

Em "Divórcio", o eixo da narrativa - a experiência de um escritor que, após encontrar o diário de sua mulher e não se conformar com o que ela diz sobre ele, vê seu corpo sem pele e retalhado, precisa recosturar-se - está orientado precisamente para a questão da identidade do sujeito mergulhado em um caos psicológico. 
Quando o medo de ter enlouquecido ficou muito forte, parei em um sinal vermelho e repeti o meu nome. Ricardo Lísias. O meu nome é Ricardo Lísias (LíSIAS, 2013, p. 78).

Nesse sentido, Galli (2010, p.51) diz que pensar a constituição do sujeito e da linguagem, por meio da identidade, é projetar uma linha que no mínimo se bifurca, se metamorfoseia de maneira descontínua de plissês (Domènech et. al. 2001) num movimento de (trans)formação.

Observemos o trecho abaixo:

A seguinte frase me mostrou que eu precisava fazer um romance: onde é que as pessoas chegam? Respirei fundo durante outro treino e concluí de novo: o que tenho em mãos é um fenômeno coletivo. Meu corpo ferido, por mais que eu ainda perca energia, precisa, portanto virar literatura. De um jeito ou de outro, a assombração inicial era verdadeira. Vim mesmo parar dentro de um livro meu. Dois contos não são suficientes para o tamanho do meu trauma (ou da pele do meu corpo). Preciso fazer um romance" (LÍSIAS, 2013, p. 172).

Essa necessidade de produção da escrita vivenciada pelo personagem Ricardo Lísias dialoga não só com o que Signori nos apresentou acima, como também com o que Arfuch (2010, p. 181) nos diz adiante:

Talvez seja esse precisamente o trabalho da narração: a recuperação de algo impossível sob uma forma que lhe dê sentido e permanência, forma de estruturação da vida e, consequentemente, da identidade.

Além dessas breves observações sobre sujeitos e subjetividades, é importante, também, identificarmos como isso se comporta de forma mais direta no gênero autoficcional. 
Souza (2011, p. 22) traz para discussão uma definição de autoficcção utilizada por Serge Doubrovsky que representa a perspectiva adotada neste ensaio:

Uma vez mais, nenhuma autobiografia, nenhuma autofiç̧ão pode ser a fotografia, a reprodução de uma vida. Não é possível. A vida se vive no corpo; a outra, é um texto. [...] A autoficção é o meio de ensaiar, de retomar, de recriar, de remodelar num texto, numa escrita, experiências vividas de sua própria que não são de nenhuma maneira uma reprodução, uma fotografia. É literalmente e literariamente uma invenção.

Vejamos o que Ricardo Lísias, durante o lançamento do livro Divórcio, respondeu ao entrevistador do site Brasileiros ${ }^{\mathrm{ii}}$ sobre o processo de autoficionalização em sua obra:

Brasileiros: Em Divórcio, há momentos em que o narrador diz que é tudo uma ficção e em outros que é tudo real. Qual versão acreditar?

Ricardo Lísias: O livro pretende discutir questões de narrador. No Brasil, as pessoas leem a literatura ainda com os padrões do realismo, e isso causa um problema técnico em relação ao narrador. O narrador modernista é totalmente diferente, é um narrador que se coloca muito em jogo, e as pessoas não percebem isso, confundem o narrador com o autor, como se fosse possível o autor falar. Isso não existe, só fala o narrador num romance. Mesmo que eu coloque o meu nome, mesmo que eu coloque a minha foto pelado, não sou eu, é uma foto, e isso, tirando um grupo de leitores, as pessoas não entendem, perdem o mais importante, que é o aspecto artístico. [...]. Esse é o cerne do meu romance. Até agora as pessoas estão tentando saber quem é quem.

Essa pergunta do entrevistador é interessante porque o questionamento "em que versão acreditar" aparece pelo fato de o escritor usar um elemento muito importante na escrita autoficcional: os biografemas. Eles aparecem no texto, conforme aponta Figueiredo (2013, p. 14), para induzir o leitor a ler o romance como uma escrita mais ou menos autobiográfica. 
Em "Divórcio", essas informações da vida do autor são utilizadas da seguinte forma para compor a escrita: uso do nome do próprio autor para identificar sua personagem principal; citação de seus romances no corpo do texto; coincidência tanto na profissão exercida por autor e personagem quanto ao que se refere a seu ritual de escrita e a sua formação acadêmica, além da inclusão de fotos familiares.

Souza (2011) fala sobre este exercício de unir o material poético ao biográfico, transformando a linguagem do cotidiano em ato literário:

[...] A presença de mediações, de terceiras pessoas, da relação oblíqua entre arte e vida é passível de intervenções entre as duas instâncias, sem que o lastro biográfico se defina pela empiria e pela interpretação textual baseada em soluções fáceis e superficiais. [...] Ainda que determinada cena recriada na ficção remeta a um fato vivenciado pelo autor, deve-se distinguir entre a busca de provas e a confirmação de verdades atribuídas ao acontecimento, do modo como a situação foi metaforizada e deslocada pela ficção (SOUZA 2011, p. 19).

Sibilia (2016, p. 250) explica que essa crescente valorização da própria experiência vivida - a espetacularização do eu - na narrativa contemporânea ganhou impulso na guinada subjetiva e completa:

Os alicerces desses relatos mais recentes tendem a se fincar no próprio eu que os assina e narra. Com uma frequência inédita, o eu protagonista - que costuma coincidir com as figuras do autor e do narrador - se torna uma instância capaz de avaliar o que se mostra e o que se diz. A autenticidade e inclusive o próprio valor dessas obras - e, sobretudo, das experiências que elas reportam - apoiam-se fortemente na biografia do autor-narrador e personagem. Em vez da imaginação, da inspiração, da perícia ou da experimentação que nutriam as peças de ficção mais tradicionais, nestes casos é a trajetória vital de quem fala (e em nome de quem se fala) que constitui a figura do autor e o legitima como tal. Tanto essas vivências 
pessoais como a própria personalidade do eu autoral, porém, também são ficcionalizadas com a ajuda de aparelhagem midiática e são convocadas para performar na visibilidade.

\section{Considerações finais}

Como vimos ao longo das análises realizadas neste artigo, o projeto de escrita que nos foi apresentado por Ricardo Lísias em "Divórcio" compactua com os argumentos utilizados pela crítica literária para tentar explicar as características que compõem o projeto estético do gênero autoficção.

Assim como em outras narrativas contemporâneas, o autor, ao utilizar elementos que compõem o processo de autoficcionalização - as relações entre autor-narradorpersonagem através do uso do $e u$, a presença de biografemas no corpo do texto, as fronteiras existentes entre o real/imaginário, identidade/subjetividade e as pontes metafóricas criadas na e pela língua -, ajuda a criar uma atmosfera de expectativas que brinca com o leitor. Isso acontece porque, segundo Viegas (2010, p. 22), as ficções avançam para a esfera pública, assim como os dados referenciais imiscuem-se nas narrativas literárias.

\section{Referências}

ARFUCH, Leonor. O espaço biográfico: dilemas da subjetividade contemporânea. Tradução de Paloma Vidal. Rio de Janeiro: EdUERJ, 2010.

BAKHTIN, M. Problemas da poética de Dostoiévski. 3 ed. Rio de Janeiro: Forense Universitária, 2005.

DELEUZE, G.; GUATTARI, F. O que é filosofia? Rio de Janeiro: Editora 34, 1992. 
DELL' ISOLA, Regina L. Péret. Intergenericidade e agência: quando um gênero é mais do que um gênero. Disponível em:

<http://linguagem.unisul.br/paginas/ensino/pos/linguagem/eventos/cd/Port/112.pdf>. Acesso em: 06 abr. 2018.

FARACO, Carlos Alberto. Linguagens \& diálogo: as ideias linguísticas do círculo de Bakthin. São Paulo: Parábola Editorial, 2009.

FIGUEIREDO, Eurídice. Formas e variações autobiográficas. A autoficção. In: Mulheres ao espelho: autobiografia, ficção, autoficção. EdUERJ, 2013. p. 13-74.

GALLI, Fernanda Correa Silveira. Escrita: (Re)construção de vozes, sentidos, 'eus'... In: CORACINI, Maria José Rodrigues Faria; ECKERT-HOFF, Beatriz Maria (Orgs.). Escrit(ur)a de si e alteridade no espaço papel-tela: alfabetização. Formação de professores, línguas materna e estrangeira. Campinas, SP: Mercado de Letras, 2010.

HALL, Stuart. A identidade cultural na pós-modernidade. 12 ed. Tradução de Tomaz Tadeu da Silva e Guacira Lopes Louro. Rio de Janeiro: Lamparina, 2015.

Kramer, Sonia. Escrita, experiência e formação: múltiplas possibilidades de criação de escrita. In: CANDAU, Vera Maria (Org.). Linguagens, espaços e tempos no ensinar e aprender. Encontro nacional de didática e prática de ensino (ENDIPE). Rio de Janeiro: DP\&A, 2001.

LíSIAS, Ricardo. Divórcio. Rio de Janeiro: Objetiva, 2013.

MARCUSCHI, Luiz Antônio. Produção textual, análise de gêneros e compreensão. Recife: Departamento de Letras: UFPE, 2005.

PIRES, Maria João. Descontinuidades do tempo e da história na pós-modernidade: breve abordagem. Revista da Faculdade de Letras, Línguas e Literaturas. Porto: 1999, p. 81-90. REIS, Carlos (Dir.). Discursos - no 12 (Literatura e Cinema), Lisboa: Universidade Aberta, 1996.

SIBILIA, Paula. O show do eu. 2 ed. Rio de Janeiro: Contraponto, 2016.

SIGNORI, Inês. Figuras e modelos contemporâneos da subjetividade. In: SIGNORI, Inês (Org.). Lingua(gem) e identidade: elementos para uma discussão no campo aplicado. Campinas, SP: Mercado de Letras, FAPESP, 1998. p. 333-383. 
SOUZA, Eneida Maria de. A crítica biográfica. In: Janelas indiscretas: ensaios de crítica biográfica. Ed. UFMG, 2011, p. 17-25

SOUZA, Eneida Maria de. Notas sobre a crítica biográfica. In: Crítica cult. Belo Horizonte: Editora UFMG, 2002. p. 111-120.

VIEGAS, Ana Claudia. Com a palavra o autor: exercícios de crítica biográfica na contemporaneidade. Cadernos de Estudos Culturais, v. 9, 2010.

\footnotetext{
'Disponível em: <http://linguagem.unisul.br/paginas/ensino/pos/linguagem/eventos/cd/Port/112.pdf>.

ii Disponível em: <http://brasileiros.com.br/2013/09/a-verdadeira-historia-ficticia-de-um-escritor-chamadoricardo-lisias/>.
}

Recebido em 2 de março de 2018. Aceito em 7 de maio de 2018. 